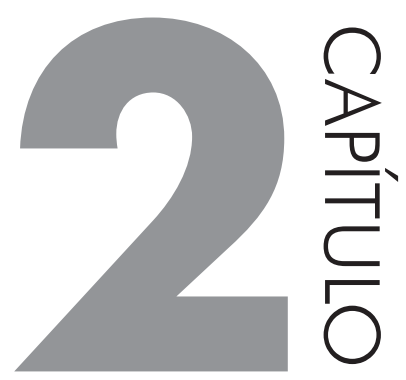

\title{
LETRAMENTO DIGITAL E LETRAMENTO ACADÊMICO: UM DIÁLOGO NECESSÁRIO
}

\section{ANGELITA MENDES, FERNANDO JOSÉ SPANHOL, MÁRCIO VIEIRA DE SOUZA}

\section{INTRODUÇÃO}

A cultura escrita, dada sua complexidade e suas múltiplas facetas, se constitui em objeto de pesquisa de diferentes áreas do conhecimento, tais como História, Sociologia, Antropologia, Psicologia, Comunicação, Linguística e tantas outras. Tal interesse revela o poder que essa modalidade da língua encerra. Mauricio Gnerre em sua importante obra Linguagem, escrita e poder assevera que a linguagem não é usada apenas para veicular informações, ela “(...) ocupa uma posição central: a função de comunicar ao ouvinte a posição que o falante ocupa de fato ou acha que ocupa na sociedade em que vive" (1985, p. 5). Essa denúncia feita por Gnerre serve para elucidar nossa compreensão sociohistórica da linguagem. Da cultura escrita interessa compreender, dentre outras possibilidades, seus usos em diferentes contextos históricos e sociais, suas funções e consequências para agrupamentos humanos, a relação que estabelece com a oralidade e com outras semioses (Bunzen, 2014).

Tal interesse pelas construções culturais mediadas pela escrita é manifestado por muitos autores nos Novos estudos do letramento, ou como foi adotado no Brasil apenas Estudos do letramento. Ao associar a esse objeto os inúmeros suportes tecnológicos por meio dos quais a escrita passou a ser produzida e dispo- 
nibilizada e as inúmeras possibilidades de acesso, vemos crescer exponencialmente as pesquisas na área. $\mathrm{Na}$ sociedade do conhecimento, as oportunidades para aprender, conhecer e ensinar foram amplificadas e com isso amplificam-se também as práticas de letramento, isto é, as práticas sociais mediadas pela escrita.

A última edição pesquisa quadrienal Retratos da Leitura no Brasil, divulgada em 2016, apresentou em seus resultados um tímido aumento da leitura, e cabe esclarecer que a definição de leitor tomada pela pesquisa é aquela que leu um livro ou partes dele nos últimos três meses. O resultado que de fato chama atenção, porém, está relacionado ao aumento da leitura em espaços públicos como bibliotecas, praças, shopping, transporte, dentre outros, em comparação com os resultados obtidos nas edições anteriores, 2007 e 2011. Outro dado importante refere-se ao que as pessoas estão fazendo no seu tempo livre. Quando perguntados sobre o que gostam de fazer em seu tempo livre, a resposta apontando assistir TV diminuiu e aumentou ler na internet, ouvir música, escrever, usando facebook, Instagram, twiter.

Esse resultado seguramente guarda relação com o avanço e com a popularização das Tecnologias Digitais de Informação e Comunicação, doravante TDIC, e incita a reflexão sobre o objeto de avaliação, o qual se pauta no conceito canônico de leitura, a leitura de livros, mas parece não incluir a leitura de textos variados, com linguagem verbal e não verbal, que grassam na internet por meio de blogs, revistas, jornais e redes sociais. Basta ver o que as pessoas estão fazendo no seu tempo livre, como bem apontou a pesquisa. A conclusão que emerge em seguida, e que norteia pesquisa institucional na educação superior em andamento pelos autores deste estudo, é a de que apenas expor as pessoas ou disponibilizar as tecnologias digitais de informação e comunicação não é suficiente para horizontalizar práticas de letramentos. O que temos verificado em nossos estudos é a necessidade de facultar aos alunos a expansão dos letramentos, hibridizando as práticas de uso da leitura e da escrita, com vistas à inclusão social e à cidadania.

Nesse contexto, interessa, a partir de um olhar interdisciplinar que envolve a educação, as tecnologias de informação e comunicação e a linguística aplicada, dentre outras áreas interessadas nesse importante binômio linguagem/tecnologia, entender como essa relação de aprendizagem está se dando no dia a dia das pessoas, na ocorrência de aprendizagem informal, para então compreender como fazer uso desse mecanismo de modo formal, na sala de aula. Assim, este artigo tematiza o letramento digital, as práticas sociais de uso da escrita e da leitura mediadas pelas tecnologias digitais, investigando como a educação pode se valer do movimento de aprendizagem informal para potencializar o letramento acadêmico, com o propósito de demonstrar a relação entre letramento digital e a potencialização dos letramentos, sobretudo do letramento acadêmico. Situados na compreensão do termo que para nós se mostra coerente e relevante no que tange 
aos estudos relativos a leitura e a escrita na educação superior, apresentamos as contribuições que os estudos do letramento podem incidir na educação como um todo e no ensino de língua, no particular, apresentando as teorizações que contribuem para a ação pedagógica a partir das práticas e dos eventos de letramento. A seguir, abordamos resultado parcial de nossos estudos, os quais têm demonstrado que o acesso às TDIC por jovens universitários em curso na área tecnológica nem sempre significa completo aproveitamento do potencial de aprendizagem que essas mídias podem oferecer e ainda obstaculiza o alcance do letramento acadêmico já que as universidades tendem a implementar as TDIC; o que nos desafia e nos leva a refletir sobre a questão de como expandir os letramentos de estudantes no ensino superior.

\section{LETRAMENTO COMO PRÁTICA SOCIAL}

O recrudescimento das práticas de leitura e escrita em consequência da popularização das mídias digitais impulsionou o uso do termo letramentos em várias áreas do conhecimento. Tal feito, quando relativo ao letramento digital, por vezes reduz o conceito à instrumentalização, limitando e restringindo seu potencial pedagógico e de inclusão digital e social.

Para compreender os distintos sentidos com que o termo letramento foi caracterizado importa retomar o momento em que foi ressignificado, no que ficou conhecido como New literacy studies, justamente para se contrapor aos estudos vigentes de literacy, cujas bases se assentavam na distinção entre letrados e iletrados, entre os dominavam o código escrito e os que não o dominavam. Os estudos da escrita então se concentravam no processo mental e individual da escrita, que em um sentido estrito a tomavam como tecnologia implicando codificação de sons em letras e decodificação de letras em sons. Brian Street, em sua obra seminal Literacy in theory and practice (1984) afirma que a escrita não pode ser tratada como neutra ou como mera técnica uma vez que as práticas de leitura e escrita são construídas na interação interpessoal, em contextos sociais e históricos. Assim, as práticas sociais de uso da escrita guardam íntima relação com os contextos em que ocorrem, dada sua estreiteza com a ação do homem, sua cultura e sua historicidade.

Shirley Heath (1982) e Brian Street (1984) são os responsáveis por importantes teorizações no campo dos Novos estudos do letramento: evento de letramento e prática de letramento. Um evento de letramento, então, se configura como qualquer ocasião em que a língua escrita é integrante da natureza das interações dos participantes e de suas estratégias e processos interpretativos (Heath, 1982, p. 319). Assim, situações em que um texto escrito esteja presente e sendo utilizado para a construção do sentido na interação dos indivíduos se caracterizam como 
eventos de letramento, sendo esses sempre visíveis. Já o conceito de práticas de letramento (Street, 1984) é proposto como sendo algo mais amplo que fornece base para as situações de uso da escrita, os eventos de letramento, implicando as vivências e os valores que permeiam a modalidade escrita da língua, ou seja, os eventos de letramento emergem de um modo de conceber e de usar a escrita. Práticas de letramento são, então, construtos sociais e devem ser analisadas a partir do contexto histórico, não se limitando ao contexto escolar já que o aceso a cultura escrita e a sua apropriação não se circunscrevem a essa esfera, elas se instituem nas relações interpessoais em geral.

Esses estudos foram divulgados no Brasil sobretudo por Angela Kleimam (1995) e por Magda Soares (1998), inaugurando uma compreensão mais ampla da diversidade dos usos sociais da escrita nos diferentes agrupamentos humanos.

As teorizações sobre a modalidade escrita da língua, advindas dos Novos estudos do Letramento, conhecido por aqui apenas como estudos do letramento, dão relevo ao papel da escrita na vida social, promovendo atividades contextualizadas na prática social e não mais se limitando às práticas de uso da língua apenas na esfera escolar. Da escola não se subtrai a função de uma das mais importantes agências de letramento (Kleimam, 1995), porém com os estudos do letramento não é mais vista como o único contexto de acesso à cultura escrita.

A complexa dimensão dos estudos do letramento, todavia, se reflete na não unicidade do conceito de letramento. Leda Tfouni (1988, 1995), pesquisando o letramento com adultos analfabetos, o entende em confronto com a alfabetização, reafirmando essa diferença ao focalizar o aspecto social letramento e o aspecto individual da alfabetização. Soares (2002) define essa diferença como uma questão de enfoque. Para Angela Kleimam, letramento é o estudo da compreensão do "desenvolvimento social que acompanhou a expansão dos usos da escrita" (Kleiman, 1995, p. 16). Assim, o conceito de letramento refere-se ao conjunto de práticas de uso da escrita nos contextos sociais, entendendo que tais práticas variam de acordo com os objetivos dos participantes, com o ambiente e com o modo como se realizam (KLEIMAN, 1995).

\section{LETRAMENTO DIGITAL COMO ESTRATÉGIA PARA POTENCIALIZAR O LETRAMENTO ACADÊMICO}

O apelo das TDIC, associadas ao acesso à internet, sobretudo nos centros urbanos, tem transformado a forma como as pessoas se informam, se comunicam e, consequentemente, como aprendem. Esse contexto permitiu um recrudescimento de práticas sociais mediadas pela leitura e pela escrita. Mensagens de texto 
foram transformadas na forma mais eficiente e usual de comunicação formal e informal. Espaços on-line hoje são locais importantes de aprendizagem, seja na busca de informação sobre como cuidar de flores, acompanhar a previsão do tempo, como manter o jardim livre de pragas, aprender uma nova receita ou um novo idioma. Embora essas informações façam uso de variadas semioses, em todos esses casos, o uso da língua prevalece, seja como recurso para a aprendizagem ou como objetivo dessa aprendizagem (Barton, 2013). Em todos esses casos as pessoas estão participando de novas práticas de leitura e de escrita, de novos letramentos. Logo, a tela das mídias digitais configuradas como espaço de escrita e de leitura traz não apenas novas formas de acesso à informação, promove também novos processos cognitivos, novas formas de aprendizagem, novas maneiras de ler e de escrever.

A perspectiva dos estudos do letramento permite entender as práticas de uso da escrita como práticas sociais que tem lugar em contextos específicos e para fins específicos (Kleiman, 1995). Logo, compreender a abrangência da escrita na vida social nos permite pensar e propor atividades contextualizadas na prática social de uso da escrita levadas a efeitos por nossos estudantes, oriundos de diferentes camadas sociais, com diferentes conhecimentos e informações sobre as coisas que estão no mundo. Além disso, diferentes suportes para leitura e escrita promovem práticas sociais de uso da escrita distintas, isto é, diferentes espaços de leitura e escrita, diferentes mecanismos de produção e difusão geram diferentes letramentos (Soares, 2002). Nesse sentido importa cotejar os conceitos de letramento digital e letramento acadêmico, no âmbito dos estudos do letramento com vistas a demonstrar tais teorizações podem favorecer a formação de nossos estudantes.

O resultado preliminar de nossa pesquisa, ora em andamento, confirma que os diferentes letramentos trazidos pelos alunos compõem o universo da educação superior, tanto quanto da educação básica, e que a distância entre os letramentos dos alunos e o letramento acadêmico figura entre as principais causas da desistência e do baixo rendimento acadêmico. Os letramentos são variados tanto quanto são variados os usos da escrita na sociedade contemporâneas, nas suas diferentes esferas da atividade humana, resultado de processos históricos que vêm determinando os diferentes gêneros do discurso orais e escritos, incluindo o uso da escrita em novos suportes tecnológicos (Goulart, 2014). Os gêneros discursivos, uma das muitas contribuições de Bakhtin (1997) para os estudos da linguagem, são tipos relativamente estáveis de enunciados, elaborados para atender as diferentes necessidades sociais das pessoas. Segundo esse autor, "A experiência verbal individual do homem toma forma e evolui sob efeito da interação continua e permanente com os enunciados individuais do outro (1992, p. 313)". 
Lea e Street (1998) definem letramento acadêmico como os processos envolvidos na aquisição apropriada e nos usos efetivos da escrita nesse contexto, o que significa se apropriar das práticas específicas da academia, incluindo os gêneros específicos mobilizados nessa esfera, bem como os modos de agir nos eventos. Logo, para além dos eventos de letramento acadêmico aos quais os alunos estão expostos, urge tentar uma aproximação das práticas sociais de leitura e escrita de textos, das quais participam os alunos, na tentativa de articular as referências de mundo trazidas para o contexto acadêmico com as novas referências, as quais se constituem tarefa da educação socializar.

Esse movimento de voltar o olhar para as práticas de leitura e escrita às quais estão engajados os alunos remete de imediato às TDIC e para os usos que a sociedade urbana faz delas.

A escrita como um saber, um modo de conhecer, para além de uma tecnologia, se mostra cada vez mais necessária para que a constituição e o uso de novos gêneros do discurso, implicados naquelas tecnologias, sejam feitos de modo crítico quanto se espera que sejam as atividades de leitura e escrita mais sedimentadas em suportes textuais tradicionais, como livros, jornais, revistas, embalagens, entre outros. (Goulart, 2014, p. 4)

São muitos os desafios adicionais que as TDIC nos impõem relativos a leitura e a escrita, dentre muitos, ensejam diferentes condições de produção, de ler e de escrever, demandando novas estratégias de leitura e de escrita, uma vez que a interação com o texto se dá com uma dinâmica diferente daquela verificada no papel. Logo, destinar atenção a como os jovens estão interagindo por meio da escrita nas mídias digitais permite compreender o uso social aí contido e expandir essas práticas. Esse movimento para o estabelecimento de práticas sociais que demandem a escrita e a leitura em tecnologias digitais define nosso entendimento de letramento digital.

A expansão do letramento está associada a sua hibridização, isto é, do local para o global, o que implica conhecer os usos sociais da escrita feitos pelos alunos para então facultar-lhes a inserção em práticas outras, que apresentem outras vozes e outros conhecimentos.

Ao planejar ações metodológicas com vista a horizontalização das representações de mundo por partes desses alunos no que respeita aos usos da escrita importa tanto quanto possível empreender um trabalho de hibridização entre letramentos vernaculares e dominantes (Street, 2003). Esse processo de hibridização consiste em considerar as vivências dos alunos de modo a expandir, a horizontalizar essas vivências com a língua; o que não deve ser confundido com verticalização das experiências dos alunos uma vez que essa estrutura enseja a valoração das práticas trazidas pelos alunos. 


\section{CONSIDERAÇÕES FINAIS}

"Entender o que os homens fazem com a escrita implica entender os homens na configuração social, cultural e histórica em que vivem.” (Cerruti-Rizatti, 2009 , p. 4)

$\mathrm{Na}$ perspectiva sociocultural de leitura e escrita assumida aqui, que parte do que as pessoas fazem com a linguagem escrita em suas vidas, intentamos demonstrar a necessidade da horizontalização das práticas letradas de nossos estudantes, tomando o natural interesse pelas mídias digitais para potencializar o letramento digital e, assim, como estratégia para ampliar o letramento acadêmico. Tal compreensão decorre da perspectiva histórico-cultural à qual este estudo está filiado, considerando que a constituição de sujeito, de linguagem e de conhecimento estão interligadas e que para nos aproximarmos das orientações de letramento dos nossos alunos é preciso compreendê-las de forma plural.

Compreender a relação que se estabelece entre sujeitos e tecnologias digitais, as linguagens e as sensibilidades desencadeadas por essa relação e as aprendizagens decorrentes dela, se configuram contemporaneamente como caminhos que podem levar à expansão dos letramentos dos estudantes, isto é, a expansão das práticas sociais de uso da escrita e da leitura.

A expansão dos letramentos, atrelada a uma abordagem de aprendizagem significativa da língua escrita, depende do olhar atento para o entorno sócio histórico em que os alunos estão situados, bem como para as suas vivências.

Nessa perspectiva, os estudos do letramento se apresentam como horizonte ético e político para a ação pedagógica nos espaços educativos (Goulart, 2014), fornecendo teorizações que municiam nossos estudos, os quais apontam para a necessidade de fortalecer os sujeitos em processo de formação, permitindo que compreendam o papel das práticas de leitura e escrita na sua vida social e na sua autonomia para continuar a aprendendo ao longo da vida.

\section{REFERÊNCIAS}

Bakhtin, Mikhail. (1997). A interação verbal. In: Bakhtin, M. Marxismo e filosofia da linguagem. (p. 110-127) São Paulo: Hucitec. . (2003). Estética da criação verbal. São Paulo: Martins Fontes.

Barton, David \& LEE, Carmen. (2015). Linguagem online. São Paulo: Parábola editorial. Bunzen, Claudio. (2014). Apresentação. In: Street, B. Letramentos sociais. São Paulo: Parábola editorial.

Cerutti-Rizzati, Mary Elizabeth. (2009). Apropriação sociocognitiva da escrita: uma discussão sobre a dimensão intrassubjetiva da linguagem. Letras de Hoje, v. 44, n. 3. 
Disponível em: <http://revistaseletronicas.pucrs.br/ojs/index.php/fale/ issue/view/390> Acesso em 13 de dezembro de 2017.

Coscarelli, Carla \& Ribeiro, Ana. (2017). Letramento digital. Belo Horizonte: Autêntica editora.

Geraldi, João Wanderley. (2014). A produção dos diferentes letramentos. Bakbtiniana, São Paulo, 9 (2): 25-34, ago./dez. 2014.

Gneree, Mauricio. (1985). Linguagem, escrita e poder. São Paulo: Martins Fontes.

Goulart, C. (2017). Letramento e novas tecnologias: questões para a prática pedagógica. In: Coscarell, C. Ribeiro. Letramento digital. Belo Horizonte: Autêntica editora.

Heath, Shirley. (1982). What no bedtime story means: narrative skills at home and school. Language and Society, v. 11, p. 49-76.

Kleiman, Angela. (1995). Modelos de letramento e as práticas de alfabetização na escola. In: Kleiman, Angela (org.). Os significados do letramento: uma nova perspectiva sobre a prática social da escrita. Campinas: Mercado de Letras, p. 15-61.

(1998b). A construção de identidades em sala de aula: um enfoque interacional. In: Signorini, Inês (org.) Linguagem e identidade: elementos para uma discussão no campo aplicado. Campinas: Mercado de Letras; São Paulo: Fapesp, p. 115-138.

. (2006). Professores e agentes de letramento: identidade e posicionamento social. Revista Filologia e Linguística Portuguesa, n. 8, São Paulo, p. 409-424.

. (2007). Letramento e suas implicações para o ensino de língua materna. Signo, v. 32, n. 53, Santa Cruz do Sul, p. 1-25, dez.

- (2010). Trajetórias de acesso ao mundo da escrita: relevância das práticas não escolares de letramento para o letramento escolar. Perspectiva, v. 28, n. 2, Florianópolis, p. 375-400, jul./dez. Disponível em: https://periodicos. ufsc.br/index.php/ perspectiva/ article/view/2175-795X.2010v28n2p375/pdf.

Lea, Mary \& Street, Brian. (2006). The academic literacies model: theory and applications. Theory into practice, 45(4), p. 368-377.

Soares, Magda Becker. (1998) Letramento: um tema em três gêneros. Belo Horizonte: Autêntica.

. (2002). Novas práticas de leitura e escrita: letramento na cibercultura. Educ. Soc., Campinas, v. 23, n. 81, p. 143-160, dez. Disponível em http://www.cedes.unicamp. br. Acesso em 08/10/2017.

. (2003). Alfabetização: a ressignificação do conceito.

Alfabetização e Cidadania - Revista de Educação de Jovens e Adultos, n. 16, p. 9-17, julho. . (2004). Letramento e alfabetização: as muitas facetas. Revista Brasileira de Educação, n. 25, jan./fev./mar./abr., p. 5-17.

. (2011). Práticas de letramento e implicações para a pesquisa e para políticas de alfabetização e letramento. In: Marinho, Marildes e Carvalho, Gilcinei Teodoro (Org.) Cultura escrita e letramento. Belo Horizonte: Editora UFMG. 
Street, Brian. (1984). Literacy in theory and practice. Cambridge: Cambridge University Press.

. (1993). Cross-cultural approaches to literacy. Cambridge: Cambridge University Press.

. (2003). Abordagens alternativas ao letramento e desenvolvimento. Teleconferência Brasil sobre letramento, out.

. (2011). Os novos estudos sobre o letramento: histórico e perspectivas, In: MARINHO, M. e CARVALHO, G. (Orgs.) Cultura escrita e letramento. Belo Horizonte: Editora UFMG.

. (2014). Letramentos sociais. São Paulo: Parábola editorial.

Tfouni, Leda Verdiani. (1988) Adultos não alfabetizados: o avesso do avesso. Campinas: Pontes.

(1995). Letramento e alfabetização. São Paulo: Cortez.

Vigotsky, Lev. Semenovich. (2001). A construção do pensamento e da linguagem. São Paulo: Martins Fontes. 
